\title{
A EDUCAÇÃO INFANTIL COMO ESPAÇO DE PROMOÇÃO DA APRENDIZAGEM E DESENVOLVIMENTO DA CRIANÇA
}

\author{
Child education as a space for the promotion of child learning and development
}

La educación infantil como espacio de promoción del aprendizaje y desarrollo del niño

Jaqueline Delgado Paschoal ${ }^{*}$

Marcilene Druzian Santos* $^{* *}$

\begin{abstract}
Resumo
Nos últimos anos, tem crescido significativamente o número de estudos publicados que abordam a temática da educação infantil, suas conquistas legais, seus avanços e as contingências que ainda persistem. Nesse contexto, o propósito deste estudo, de caráter bibliográfico, é discutir a finalidade da educação infantil no cenário da educação brasileira, especialmente, em função dos avanços da legislação a partir da década de noventa. Embora, tenha havido o reconhecimento das leis e das políticas públicas sobre o direito da criança à educação de qualidade e o dever do Estado na garantia desse direito, verifica-se um descompasso entre o legislado e o efetivado. A falta de clareza sobre a especificidade dessa etapa da Educação Básica tem levado a práticas assistencialistas no trabalho com as crianças menores de três anos na creche, assim como, a um foco acentuadamente educativo com crianças de quatro e cinco anos na pré-escola. Os resultados deste estudo indicam que a formação continuada das professoras é condição essencial para a compreensão da indissociabilidade entre cuidados e educação na organização do trabalho pedagógico com as crianças. Desse modo, é necessária a elaboração, implementação e avaliação de propostas pedagógicas capazes de contribuir para o desenvolvimento integral das crianças, sobretudo no que tange ao desenvolvimento de suas diferentes linguagens.
\end{abstract}

\section{PALAVRAS-CHAVE: Legislação. Direitos. Cuidados e Educação}

\begin{abstract}
In recent years, there has been a significant increase in the number of published studies that address the theme of early childhood education, its legal achievements, its advances and the contingencies that still persist. In this context, the purpose of this bibliographic study is to discuss the purpose of early childhood education in the Brazilian educational scenario, especially in light of the advances in legislation since the 1990s. Although there has been recognition of the laws and public policies on the right of the child to quality education and the duty of the State to guarantee this right, there is a gap between the legislated and the effective. The lack of clarity about the specificity of this stage of Basic Education has led to assistential practices in working with children under three in the day care center, as well as a markedly educational focus on pre-school children with four and five year olds. The results of this study indicate that the continuous formation of teachers is an essential condition for understanding the inseparability between care and education in the organization of pedagogical work with children. Thus, it is necessary to prepare, implement and evaluate pedagogical proposals that can

\footnotetext{
* Pós-Doutora em Educação pela Universidade Estadual Paulista Júlio de Mesquita Filho, Faculdade de Ciências e Letras de Assis. Doutora em Educação pela Universidade Estadual de Maringá-UEM. Docente no Programa de Mestrado e Doutorado em Educação na Universidade Estadual de Londrina. Docente no Curso de Pedagogia do Departamento de Educação da UEL. E-mail: jaquelinedelgado@uol.com.br

** Especialista em Educação Infantil pela Universidade Estadual de Londrina. Professora de Educação Infantil na rede municipal de Londrina. E-mail: marcileneds@uol.com.br
} 
contribute to the integral development of children, especially in the development of their different languages.

KEYWORDS: Legislation. Rights. Care and Education

\section{Resumen}

En los últimos años, ha crecido significativamente el número de estudios publicados que abordan la temática de la educación infantil, sus conquistas legales, sus avances y las contingencias que aún persisten. En este contexto, el propósito de este estudio, de carácter bibliográfico, es discutir la finalidad de la educación infantil en el escenario de la educación brasileña, especialmente, en función de los avances de la legislación a partir de la década de los noventa. Aunque el reconocimiento de las leyes y de las políticas públicas sobre el derecho del niño a la educación de calidad y el deber del Estado en la garantía de ese derecho, se verifica un desajuste entre el legislado y el efectivo. La falta de claridad sobre la especificidad de esta etapa de la Educación Básica ha llevado a prácticas asistencialistas en el trabajo con los niños menores de tres años en la guardería, así como a un enfoque acentuadamente educativo con niños de cuatro y cinco años en la preescolar. Los resultados de este estudio indican que la formación continuada de las profesoras es condición esencial para la comprensión de la inseguridad entre cuidados y educación en la organización del trabajo pedagógico con los niños. De este modo, es necesaria la elaboración, implementación y evaluación de propuestas pedagógicas capaces de contribuir al desarrollo integral de los niños, sobre todo en lo que se refiere al desarrollo de sus diferentes lenguajes.

PALABRAS CLAVE: Legislación. Derechos. Cuidados y Educación

\section{INTRODUÇÃO}

A educação infantil passou por mudanças significativas ao longo das últimas três décadas, como resultado da aprovação da Constituição Federal de 1988, que reconheceu a criança como sujeito de direitos, inclusive o direito à educação desde o nascimento. Desse modo, as creches, anteriormente vinculadas à área de assistência social, passaram a ser de responsabilidade do setor educacional, pois se tomou como orientação o princípio de que essas instituições devem, prioritariamente, desenvolver um trabalho que possibilite a integração entre os aspectos relacionados aos cuidados e à educação das crianças em espaços coletivos (PASCHOAL, 2015).

Apesar do consenso sobre a função educativa das escolas infantis, verifica-se um descompasso nas concepções e práticas das professoras ${ }^{1}$ no cotidiano das instituições, pois as atividades que envolvem a rotina de cuidados, como banho, alimentação e descanso das crianças, nem sempre são reconhecidas como pedagógicas. Por outro lado, é importante ressaltar que as ações de cuidar e educar contribuem para a ampliação do repertório de aprendizagem das crianças, sobretudo quando expostas em situações de interação social.

O objetivo deste estudo, de caráter bibliográfico, é apresentar a finalidade principal da educação infantil, que é promover o desenvolvimento integral da criança de zero cinco anos de idade, de modo a contribuir para o desenvolvimento de suas diferentes linguagens.

Do ponto de vista legal, a Constituição Federal (1988) assegurou o direito de todos os cidadãos à educação e encarregou ao Estado o dever de promovê-la. Desta forma, as creches,

\footnotetext{
${ }^{1}$ Utilizaremos a palavra no feminino, visto que a grande maioria dos profissionais que atua na educação infantil são mulheres.
} 
anteriormente vinculadas à assistência social, passaram a ser de responsabilidade do setor educacional.

\begin{abstract}
Art. 205. A educação, direito de todos e dever do Estado e da família, será promovida e incentivada com a colaboração da sociedade, visando ao pleno desenvolvimento da pessoa, seu preparo para o exercício da cidadania e sua qualificação para o trabalho. Art. 208. O dever do Estado com a educação será efetivado mediante a garantia de: IV - educação infantil, em creche e pré-escola, às crianças até 5 (cinco) anos de idade. Redação dada pela Emenda Constitucional $\mathrm{n}^{\mathrm{o}}$ 53, de 2006 (BRASIL, 1988).
\end{abstract}

Efetivamente, a Carta Constituinte foi o ponto de partida para que a sociedade passasse a reconhecer os direitos das crianças e, mais especificamente, o direito destas à educação desde o nascimento, assim como, a obrigação do Estado em garantir esse direito e conferir maior autonomia aos municípios, afastando, desse modo, o regime autoritário e excessivamente concentrador anteriormente existente (BARRETO, 1998).

A fim de estabelecer a estrutura de todo o sistema de ensino e de assegurar a eficaz promoção do direito à educação, no Art. 206, a Constituição Federal (1988) determinou como princípio educacional os seguintes requisitos: igualdade de condições para o acesso e permanência na escola; liberdade de aprender, ensinar, pesquisar e divulgar o pensamento, a arte e o saber; pluralismo de ideias; gratuidade do ensino público em estabelecimentos oficiais e valorização dos profissionais da educação escolar; além de gestão democrática do ensino público e garantia de padrões de qualidade (BRASIL, 1988).

A aprovação da Lei de Diretrizes e Bases da Educação Nacional (1996) legitimou o pressuposto no texto da Constituição, visto que inseriru a educação infantil como primeira etapa da Educação Básica e determinou a função educativa dessa etapa ao destacar, no Art. 29, que sua finalidade é "promover o desenvolvimento integral da criança até cinco anos de idade, em seus aspectos físicos, psicológicos, intelectual e social, complementando a ação da família e da comunidade" (BRASIL, 1996).

Nesse sentido, a prerrogativa do desenvolvimento integral da criança, previsto na legislação, supera o caráter assistencialista e a visão preconceituosa da creche como espaço de guarda da criança pobre. No Art. 30, a LDB (1996) destaca que a educação infantil será oferecida em creches ou entidades equivalentes, para crianças de até três anos de idade, e na pré-escola, para as crianças de quatro a cinco anos de idade, sem qualquer diferenciação quanto ao cuidado, educação e acolhimento a serem proporcionados em ambas as faixas etárias. Por isso, no Artigo 31, determina que a avaliação será mediante o acompanhamento e registro do desenvolvimento das crianças, sem o objetivo de promoção, mesmo para o acesso ao ensino fundamental (BRASIL, 1996).

Embora a legislação tenha avançado em relação à educação das crianças pequenas, outros segmentos sociais, tais como organizações não-governamentais, pesquisadores da área da infância, comunidade acadêmica e população civil, também contribuíram para a ampliação do debate e para o reconhecimento da Educação Infantil como espaço eminentemente pedagógico (OLIVEIRA, 2002).

Desse modo, essa etapa da educação deve ser concebida e praticada com base em propostas pedagógicas capazes de reconhecer a criança como um ser complexo e com necessidades específicas, e que levem em consideração também as particularidades decorrentes do meio em que cada criança se insere. Daí a importância dessa instituição como espaço de promoção dos direitos das crianças, sobretudo no que diz respeito ao direito à infância e à construção de novos saberes. Para tanto, a formação inicial e continuada das professoras é condição primordial, visto que o conhecimento teórico e metodológico acerca do desenvolvimento humano, atrelado à organização do trabalho pedagógico na educação 
infantil, possibilita a qualidade dos serviços prestados às crianças e suas famílias (PASCHOAL, 2015).

\title{
Trabalho pedagógico de qualidade na Educação Infantil
}

\begin{abstract}
A Política Nacional de educação infantil (2006a) determinou a indissociabilidade entre cuidados e educação na organização do trabalho pedagógico, superando a visão adultocêntrica, segundo a qual a criança é concebida apenas como um vir a ser e, portanto, necessita ser "preparada para" (BRASIL, 2006a). As principais orientações desse documento indicam a expansão da oferta de vagas, o fortalecimento das instâncias competentes e, sobretudo, a garantia de uma "concepção de educação e cuidado como aspectos indissociáveis das ações dirigidas às crianças e a promoção da melhoria da qualidade do atendimento em instituições de Educação Infantil" (BRASIL, 2006a, p. 10). Essa política reconhece que a "educação infantil tem função diferenciada e complementar à ação da família, o que implica uma profunda, permanente e articulada comunicação entre elas" (BRASIL, 2006a, p. 17). Como objetivos, o referido documento orienta:
\end{abstract}

\begin{abstract}
As instituições de Educação Infantil devem elaborar, implementar e avaliar suas propostas pedagógicas a partir das Diretrizes Curriculares Nacionais para Educação Infantil e com a participação das professoras e dos professores; As propostas pedagógicas das instituições de Educação Infantil devem explicitar concepções, bem como definir diretrizes referentes à metodologia do trabalho pedagógico e ao processo de desenvolvimento/aprendizagem, prevendo a avaliação como parte do trabalho pedagógico, que envolve toda a comunidade escolar; Fortalecer parcerias para assegurar, nas instituições competentes, o atendimento integral à criança, considerando seus aspectos físico, afetivo, cognitivo/lingüístico (sic.), sociocultural, bem como as dimensões lúdica, artística e imaginária; Assegurar a valorização das professoras e professores de Educação Infantil, promovendo sua participação em Programas de Formação Inicial para professores em exercício, garantindo, nas redes públicas, a inclusão nos planos de cargos e salários do magistério (BRASIL, 2006a, p. 17).
\end{abstract}

Para atender o previsto na Política Nacional de Educação Infantil (2006a), o Ministério da Educação publicou um documento intitulado "Parâmetros Nacionais de Qualidade para a Educação Infantil” (2006b), cujo objetivo não foi estabelecer padrões mínimos nem máximos, mas "requisitos necessários para uma educação infantil que possibilite o desenvolvimento integral da criança até os cinco anos de idade, em seus aspectos físico, psicológico, intelectual e social" (BRASIL, 2006b, p. 9). Desse modo, o intuito foi estabelecer um padrão de referência que promova igualdade de oportunidades educacionais e leve em conta as diferenças, diversidades e desigualdades de nosso imenso território e das muitas culturas nele presentes (BRASIL, 2006b).

Cumpre destacar que a elaboração de uma proposta pedagógica que respeite os direitos da criança, segundo os Parâmetros Nacionais de Qualidade (2006b), deve se pautar, entre outros, nos seguintes critérios: integração entre cuidados e educação; atividades orientadas que promovam diferentes aprendizagens infantis; reconhecimento da identidade pessoal das crianças, de suas famílias, dos professores e de outros profissionais; inclusão das crianças com necessidades educacionais especiais; e disponibilização de materiais e equipamentos adequados para o pleno funcionamento das escolas infantis (BRASIL, 2006b).

Embora os documentos apresentados tenham orientado questões relevantes a serem consideradas no cotidiano das instituições, coube à Resolução $\mathrm{n}^{\circ} 5$, de 17 de dezembro de 2009, que fixa as Diretrizes Curriculares Nacionais para a Educação Infantil, estabelecer

Revista Educação e Fronteiras On-Line, Dourados/MS, v.8, n.24, p.102-112, set./dez. 2018105 
normas para a construção e implementação de propostas pedagógicas para as escolas infantis. Nesse sentido, esse documento determinou que os seguintes princípios sejam observados e respeitados:

\begin{abstract}
Art. $6^{\circ}$ - I: Éticos: da autonomia, da responsabilidade, da solidariedade e do respeito ao bem comum, ao meio ambiente e às diferentes culturas, identidades $\mathrm{e}$ singularidades; II- Políticos: dos direitos de cidadania, do exercício da criticidade e do respeito à ordem democrática; III- Estéticos: da sensibilidade, da criatividade, da ludicidade e da liberdade de expressão nas diferentes manifestações artísticas e culturais (BRASIL, 2009, p. 02).
\end{abstract}

Ao reconhecer a educação infantil como "espaços institucionais, não domésticos, que constituem estabelecimentos educacionais públicos e privados que educam e cuidam de crianças de zero a cinco anos de idade" (BRASIL, 2009, p. 01), esse documento reitera a função eminentemente educativa desse nível de ensino e destaca que o projeto pedagógico deve orientar todas as ações da instituição, sobretudo no que diz respeito às aprendizagens das crianças. Desse modo, o currículo deve ser entendido como um conjunto de práticas que busque articular as experiências e os saberes das crianças com os conhecimentos que fazem parte do "patrimônio cultural, artístico, ambiental, científico e tecnológico, de modo a promover seu desenvolvimento pleno" (BRASIL, 2009, p. 01).

Nesse sentido, a proposta pedagógica das instituições deve oferecer "condições e recursos para que as crianças usufruam seus direitos civis, humanos e sociais; possibilitando tanto a convivência entre crianças e entre adultos e crianças quanto à ampliação de saberes e conhecimentos de diferentes naturezas" (BRASIL, 2009, p. 02). Além disso, as Diretrizes também sinalizam para a importância do respeito à infância das crianças em espaços coletivos, que devem promover "a igualdade de oportunidades educacionais entre as crianças de diferentes classes sociais no que se refere ao acesso aos bens culturais e às possibilidades de vivência da infância" (BRASIL, 2009, p. 02), assim como, desenvolver:

Novas formas de sociabilidade e de subjetividade comprometidas com a ludicidade, a democracia, a sustentabilidade do planeta e com o rompimento de relações de dominação etária, socioeconômica, étnico-racial, de gênero, regional, linguística e religiosa (BRASIL, 2009, p. 02).

Diante disso, é possível afirmar que a legislação e as políticas públicas trouxeram grandes avanços no que diz respeito ao modo de se organizar e implementar o trabalho pedagógico na educação infantil, visto que tanto as ações que envolvem a rotina do banho, da alimentação e do descanso, quanto as relacionadas às atividades orientadas, devem se basear numa concepção integrada de aprendizagem e desenvolvimento infantil. Daí a importância da organização de uma rotina que considere as necessidades e as especificidades das crianças (BARBOSA, 2006).

Segundo Barbosa (2006), a rotina é importante, pois além de servir para orientar as ações das crianças e organizar o trabalho das professoras, constitui um excelente instrumento para o desenvolvimento das primeiras, ao possibilitar a estruturação da independência e da autonomia, bem como, a ampliação da socialização infantil. Além disso, a rotina é implementada para organizar o tempo e o espaço das instituições.

A rotina é compreendida como uma categoria pedagógica da Educação Infantil que opera como uma estrutura básica organizadora da vida cotidiana diária em certo tipo de espaço social, creches ou pré-escola. Devem fazer parte da rotina todas as atividades recorrentes ou reiterativas na vida cotidiana coletiva, mas nem por isso precisam ser repetitivas (BARBOSA, 2006, p. 201). 
Como a integração entre cuidados e educação é indissociável nas ações das professoras, a rotina diária deve se pautar nesse binômio para a promoção de situações de aprendizagem orientadas e de brincadeiras no trabalho com as crianças, pois "a educação infantil é um direito das crianças e de seus familiares" (MORENO, 200, p. 54). Nesse sentido, faz se necessário, segundo a autora:

Uma educação infantil que respeite os direitos da criança em um espaço adequado, rico em estímulos, agradável aos olhos infantis, num tempo bem planejado, capaz de satisfazer suas necessidades em busca da construção de novos saberes e da descoberta do mundo a sua volta, brincando e sendo feliz nesta fase da vida que merece toda nossa atenção, a infância (MORENO, 2007, p. 55).

$\mathrm{Na}$ ótica de Moreno (2007, p. 56) é fundamental observar "as crianças pequenas nos seus gestos, olhares, choro; com as maiores é possível dialogar, negociar, combinar", sobretudo nos momentos que envolvem a rotina da instituição. É importante ressaltar que toda a equipe pedagógica é responsável pela organização da rotina, que deve levar em consideração a faixa etária da criança e oferecer um atendimento altamente qualificado, pois:

O papel da educação infantil e do educador concretiza-se no ideal de recuperação da infância perdida nos tempos modernos para inserir a criança no mundo do conhecimento, na condição de ser alfabetizada na leitura de mundo, na leitura interpretativa de tudo o que está ao seu redor sem perder a natureza, a magia, a fantasia, o mundo maravilhoso do ser criança e propiciar-lhes desenvolvimento integral, seguro e significativo (ANGOTTI, 2006, p. 26).

Para Barbosa (2006), a organização da rotina reflete, de maneira significativa, a concepção de criança, de infância e de educação das escolas infantis, além de constituir uma "visão própria como concretização paradigmática de uma concepção de educação e cuidado" assim, pode-se afirmar que a rotina e a concepção de educação e cuidado, implementadas em uma instituição infantil, "sintetizam o projeto pedagógico das instituições e apresentam a proposta de ação educativa dos profissionais” (BARBOSA, 2006, p. 35).

Convém registrar que, ao organizar as atividades, a professora deve levar em conta a participação das crianças como ferramenta de maior dinamicidade e interatividade, segundo Barbosa (2006). O trabalho em conjunto propiciará, inegavelmente, maior sensibilidade das crianças no que diz respeito ao tempo e ao espaço, o que as auxiliará no entendimento das relações sociais. Assim, todo trabalho realizado deve levar em consideração não só a realidade sociocultural das crianças, mas "o desenvolvimento infantil e os interesses específicos que as crianças manifestam, bem como os conhecimentos acumulados historicamente pela humanidade a que todos têm direito" (KRAMER, 1991, p. 50).

Nesse sentido, segundo Barbosa (2006), a palavra rotina contém dois aspectos implícitos, que dizem respeito às noções de espaço e tempo. A noção de espaço relaciona-se com a "rota de deslocamentos espaciais previamente conhecida; por outro lado, a noção de tempo está ligada ao desencadeamento de atos que se sucedem numa determinada frequência de tempo" (BARBOSA, 2006, p. 45). Para a autora, em relação ao tempo é importante esclarecer que, do ponto de vista da história, houve uma profunda revolução sobre o tema, pois o homem passou a organizar sua vida diária de maneira sequenciada, e este ordenamento dos acontecimentos se deu a partir de um artefato central, o relógio.

Para melhor se organizar, o homem passou a se utilizar de instrumentos capazes de "medir o tempo", sendo que a escola não ignorou esta sistemática. As instituições de ensino também se organizam de acordo com o tempo, assim, professores e crianças devam se 
enquadrar nas atividades e nos espaços propostos ao longo do período escolar (BARBOSA, 2006).

Acorsi (2007, p. 55) afirma que "o tempo escolar educa, controla, determina aprendizagens; marcado pelo relógio, o tempo da escola é único, medido e deve ser apre(e)ndido pelos sujeitos". Na educação infantil, por exemplo, observa-se a hora da roda de conversa, a hora da experiência, a hora do lanche, a hora do banho, a hora de lavar as mãos, dormir, escovar os dentes etc., de modo que as atividades ficam distribuídas, organizadamente, no tempo disponível. Nesse sentido, segundo Frago e Escolano (1998, p. 43-44), o tempo é:

\begin{abstract}
Um organizador da vida da comunidade e também da vida da infância. Ele marca as horas de entrada e de saída da escola, os tempos de recreio e todos os momentos da vida da instituição. A ordem temporal se une, assim, à do espaço para regular a organização acadêmica e para pautar as coordenadas básicas das primeiras aprendizagens.
\end{abstract}

As atividades devem ser planejadas de acordo com os múltiplos momentos diferenciados, tais como: horário de chegada, hora da higiene, das brincadeiras, da alimentação, da leitura de livros de histórias e das atividades dirigidas. Independentemente do momento e das metodologias aplicadas, as atividades devem ter como intuito o desenvolvimento das crianças em todos os aspectos. A organização das atividades, no tempo, pode ser planejada a partir de três necessidades básicas das crianças: as biológicas, ligadas ao repouso, à higiene, à alimentação e à idade; a psicológica, atrelada às condições pessoais de cada indivíduo, ou seja, à percepção das crianças, à velocidade de seu raciocínio e à personalidade das mesas; e, por fim, as necessidades sociais e históricas, relacionadas à cultura (FRAGO; ESCOLANO, 1998).

O tempo é essencial na atividade docente e pode ser utilizado das mais diversas maneiras, de modo a conferir dinamicidade às propostas pedagógicas, tornando mais vivos e completos os trabalhos diários. O espaço da sala de aula, onde são praticadas as atividades pedagógicas, "constitui importante ferramenta no aprendizado em geral, porque não é neutro e sempre educa" (FRAGO; ESCOLANO, 1998, p. 75).

Não basta um espaço abstratamente razoável, pois este deve ser capaz de atender a proposta e a prática pedagógica da professora e, ao mesmo tempo, ser acolhedor para as crianças. Para que se atinja tal nível de harmonia, é fundamental que se compreenda as dimensões do ambiente em seus aspectos físicos, funcionais, temporais e relacionais. Só após o conhecimento e a adequação das dimensões do espaço, o docente poderá legitimá-lo como um elemento curricular (HORN, 2006). Além dessas questões, é importante ressaltar que o trabalho pedagógico deve articular "a realidade sociocultural das crianças, o desenvolvimento infantil e os interesses específicos que as crianças manifestam, bem como os conhecimentos acumulados historicamente pela humanidade a que todos têm direito" (KRAMER, 1991, p. $50)$.

Por outro lado, é de extrema importância que o docente reserve um momento da rotina para que a criança tenha possibilidade de escolher o canto com o qual se identifica e no qual deseja brincar, já que essa autonomia possibilitará o desenvolvimento de suas potencialidades. Assim, revela-se oportuno preencher o espaço com elementos subjetivos, capazes de interagir com a criança e despertar nela a vontade de construir uma realidade diferente, de forma que haja inovação, troca e experiência mútua. Além disso, segundo Acorsi (2007, p. 49):

A compressão tempo-espaço traz à tona, de forma bastante significativa as relações de poder que agem diretamente na sua produção, refletidas tanto pela sua capacidade 
de mobilidade quanto pela sua capacidade de controle, colocando os sujeitos como colaboradores em um momento e como prisioneiros em outro.

Horn (2006, p.28) ressalta que "é no espaço físico que a criança consegue estabelecer relações entre o mundo e as pessoas, transformando-o em um pano fundo no qual se inserem emoções; essa qualificação do espaço físico é que o transforma em um ambiente". Desse modo, é importante que a professora conheça o espaço e suas nuances e saiba utilizá-lo, a cada momento, como um parceiro de trabalho de acordo com a maneira mais apropriada. Ao agir dessa maneira, o docente possibilitará que esse importante elemento legitime seu trabalho e forneça melhores condições para o aprendizado das crianças em todos os aspectos (HORN, 2006).

Um elemento importante para a organização da rotina diz respeito à sequência de atividades, pois essa sequência contribui para que a criança compreenda o contexto em que está vivendo, "que está em profunda inter-relação com as rotinas organizadas social e politicamente" (BARBOSA, 2006, p. 48). Para organizar essas atividades no tempo, é fundamental levar em consideração três diferentes necessidades das crianças:

\begin{abstract}
As necessidades biológicas das crianças como as relacionadas ao repouso, à alimentação, à higiene, e à sua faixa etária; as necessidades psicológicas que se referem às diferenças individuais como, por exemplo, o tempo e o ritmo que cada uma necessita para realizar as tarefas propostas; as necessidades sociais e históricas que dizem respeito à cultura e ao estilo de vida, como as comemorações significativas para a comunidade onde se insere a escola e também as formas de organização institucional da escola infantil (BARBOSA; HORN, 2001, p. 68).
\end{abstract}

É importante ressaltar que "quanto menor a criança, mais as atitudes e procedimentos de cuidado do adulto são de importância fundamental para o trabalho educativo que realiza com ela" (BRASIL, 1998, p. 15). Sobre essa questão, Callil (2010) destaca que um bom ambiente é aquele:

Capaz de contemplar os modos de vida próprios da criança; que favoreça sua liberdade, suas vozes e suas diversas formas de expressão; que promova a aprendizagem cognitiva, social e afetiva; que privilegie os espaços de brincadeira; que propicie diversos tipos de interação; que possibilite escolhas; que seja atrativo, alegre e acolhedor proporcionando uma situação de bem estar e segurança (CALLIL, 2010, p. 67).

Propiciar experiências educativas em todos os momentos da rotina "é compreender como ajudar o outro a se desenvolver como ser humano; cuidar é valorizar e ajudar a desenvolver capacidades" (BRASIL, 1998, p. 24). Pelo exposto, reiteramos que se faz necessária uma ação integrada entre cuidados e educação nos momentos que envolvem a rotina da educação infantil.

O conhecimento do desenvolvimento infantil e a valorização das características individuais das crianças são essenciais para a promoção de contextos de aprendizagem prazerosos. Isso quer dizer que o ensino, nesse nível educativo, não pode ser confundido com o modelo de escolarização dos anos iniciais e, muito menos, com um local de simples guarda das crianças. O cuidar deve acompanhar o ato de educar e ensinar, para que se possa otimizar o desenvolvimento das capacidades das crianças, nas suas diferentes formas de linguagem.

Sobre essa questão, Pasqualini e Martins (2008, p. 78) enfatizam que os cuidados e a educação constituem elos mais que significativos e, portanto, inseparáveis, uma vez que "é impossível cuidar de crianças sem educá-las", considerando-se que a dicotomia entre essas dimensões ocorre somente quando a superficialidade se torna parte da ação de quem lida com 
as crianças. Assim, "o cuidado está presente em alguma medida em todos os níveis de ensino e em toda relação educativa, não constituindo uma dimensão exclusiva ou específica da educação infantill” (PASQUALINI; MARTINS, 2008, p. 79).

$\mathrm{Na}$ perspectiva das autoras, as escolas infantis devem constituir espaços educativos, porém, não escolarizantes, assumindo, concomitantemente, a dimensão do cuidado e as práticas educativas, superando, portanto, um trabalho que, do ponto de vista histórico, esteve associado, exclusivamente, à assistência da criança pobre. Desse modo, "a prática pedagógica considera os saberes produzidos no cotidiano por todos os sujeitos envolvidos no processo: crianças, professores, pais, comunidade e outros profissionais" (BRASIL, 2006a, p. 26). A implementação das leis, no Brasil, reforçou a importâncida de um trabalho que integra cuidados e educação, de modo a promover o desenvolvimento integral da criança e, não mais, uma educação moralizante e disciplinadora como ocorreu nas origens desse nível de atendimento institucional.

\section{CONSIDERAÇÕES FINAIS}

Os resultados desse estudo indicam que é necessário que as professoras compreendam a integração entre as ações de cuidar e educar como indissociáveis na educação infantil. Por isso, o conhecimento teórico e metodológico dessas profissionais é condição para a consolidação dessa etapa da Educação Básica. A superação do caráter assistencialista só será possível mediante um trabalho que não dicotomize as rotinas relacionadas ao banho, à alimentação, ao descanso, entre outras atividades, daquelas entendidas como pedagógicas.

Nesse cenário, a Constituição Federal (1988) avançou quando reconheceu o direito da criança à educação, desde o nascimento, e a obrigação do Estado em garantir esse direito, bem como, quando conferiu maior autonomia aos municípios, que passaram a adotar políticas públicas e medidas efetivas para a melhoria e manutenção do sistema de ensino infantil, que passou a ser visto como um direito da criança, independentemente da classe social de origem da mesma. Essas mudanças também repercutiram positivamente na atuação das professoras que antes realizavam funções distintas, pois as monitoras acompanhavam as brincadeiras das crianças e as professoras se encarregavam do desenvolvimento intelectual. Graças às determinações legais das últimas décadas, foi possível um atendimento pedagógico que visa a possibilitar a aprendizagem e o desenvolvimento integral da criança.

O trabalho pedagógico deve articular a realidade sociocultural das crianças aos seus interesses específicos e aos conhecimentos acumulados historicamente pela humanidade. Neste contexto, se faz necessária a elaboração e a implementação de propostas pedagógicas capazes de entender a criança como um ser complexo nos aspectos emocionais, sociais, cognitivos, psicomotores, levando em consideração, sobretudo, suas particularidades, que decorrem do meio em que está inserida, com sua cultura e configuração história, social e econômica específicas, o que redunda em necessidades também específicas.

\section{REFERÊNCIAS}

ACORSI, Roberta. (Des)encaixes: espaço e tempo na escola contemporânea. Dissertação (Mestrado). Canoas: [s.n.], 2007. 
ANGOTTI, Maristela. Educação infantil: para que, para quem e por quê? Campinas: Alínea, 2006.

BARBOSA, Maria Carmen Silveira. Por amor e por força: rotinas na educação infantil. Porto Alegre: Artmed, 2006.

BARRETO, Ângela Maria Rabelo Ferreira. Situação atual da educação infantil no Brasil. In: BRASIL, Ministério da Educação e do Desporto. Subsídios para o credenciamento e funcionamento das instituições de educação infantil. v. 2. Coordenação Geral de educação infantil. Brasília, MEC/SEB, 1998.

BRASIL. Constituição da República Federativa do Brasil. Brasília, DF: Senado Federal, 1988.

BRASIL. Lei de Diretrizes e Bases da Educação Nacional. Lei no 9394, de 20 de dezembro de 1996. Dispõe sobre as Diretrizes e Bases da Educação Nacional. Brasília, DF: MEC, 1996.

BRASIL. Referencial Curricular Nacional para a Educação Infantil. Brasília: Secretaria de Educação Fundamental, 1998.

BRASIL. Política Nacional de Educação Infantil: pelos direitos das Crianças de Zero a Seis Anos à Educação. Brasília: MEC/SEB, 2006a.

BRASIL. Ministério da Educação e do Desporto. Secretaria de Educação Básica. Parâmetros Nacionais de Qualidade para a educação infantil. v 1. Brasília, DF: MEC/SEB, 2006b.

BRASIL. Parecer CNE/CEB 020/2009; Resolução CNE/CEB N. 5/2009. Diretrizes Curriculares Nacionais para a Educação Infantil. Brasília, DF: Conselho Nacional de Educação/Câmara da Educação Básica, 2009.

CALIL, Ana Maria Gimenes Corrêa. Formar e formar-se no berçário: um projeto de desenvolvimento profissional no contexto de um centro de educação infantil. Dissertação de Mestrado. USP, São Paulo, 2010.

FRAGO, Antonio; ESCOLANO, Augustín. Currículo, espaço e subjetividade: a arquitetura como programa (trad. Alfredo Veiga-Neto). Rio de Janeiro, DP\&A, 1998.

HORN, Maria das Graças. Projetos pedagógicos na educação infantil. Porto Alegre. Ed. Artes Médicas, 2006.

KRAMER, Sonia. Com a pré-escola nas mãos: uma alternativa curricular para a educação infantil. 2. ed. São Paulo: Ática, 1991.

MORENO, Gilmara Lupion. Organização do trabalho pedagógico na Educação Infantil. In: PASCHOAL, Jaqueline. Delgado. (Org.) Trabalho pedagógico na educação infantil. Londrina, 2007. p. 53-63.

OLIVEIRA, Zilma Ramos de. Educação Infantil: fundamentos e métodos. São Paulo: Cortez, 2002. (Coleção docência em formação)

PASCHOAL, Jaqueline Delgado. Entre os saberes e práticas das professoras de educação infantil: um estudo sobre os cuidados na primeira infância. POIÉSIS. Unisul, Tubarão, v.9, n.15, p. 63 - 79, Jan/Jun 2015. pp. 63-79. Disponível em:

$<$ http://www.portaldeperiodicos.unisul.br/index.php/Poiesis/article/view/2716/2115>. Acesso em: $<13$ fev. 2017>. 
PASQUALINI, Juliana C.; MARTINS, Lígia Martins. A Educação Infantil em busca de identidade: análise crítica do binômio cuidar-educar e da perspectiva anti-escolar em Educação Infantil. Psicologia da Educação. São Paulo, n. 27, 2008. pp. 71-100. Disponível em: <http://pepsic.bvsalud.org/pdf/psie/n27/v27a05.pdf>. Acesso em: <20 jan. 2017>.

Recebido em: 15 de março/2018

Aprovado em: 20 de julho/2018 